\title{
REVIEW
}

\section{The impact of the UK General Practice Airways Group (GPIAG) - an international perspective}

\author{
*Ron Tomlins ${ }^{\mathrm{a}, \mathrm{b}}$, Sian Williams ${ }^{\mathrm{c}}$ \\ adjunct Associate Professor, Discipline of General Practice, Western Clinical School, University of Sydney, Australia \\ ${ }^{\mathrm{b}}$ Treasurer, International Primary Care Respiratory Group \\ ${ }^{c}$ Executive Officer, International Primary Care Respiratory Group
}

Received 29th April 2007; accepted 7th May 2007

\begin{abstract}
Summary company and charity saved the IPCRG much anguish.

(C) 2007 General Practice Airways Group. All rights reserved.

R Tomlins and S Williams. Prim Care Resp J 2007; 16(3): 140-144.

doi:10.3132/pcrj.2007.00037
\end{abstract}

The impact of the UK General Practice Airways Group (GPIAG) over the past 20 years is discussed from an international perspective.

The formation of the International Primary Care Respiratory Group (IPCRG) following the GPIAG conference in 2000, and the role of the Primary Care Respiratory Journal in publishing high quality primary care respiratory research, have been seminal elements in the development of the discipline of primary care respiratory medicine internationally. Research, guidelines development, education, and advocacy, are other areas where the GPIAG has provided a model or shown the way. At a more pragmatic level, the experience of the GPIAG in building a relationship with sponsors and in negotiating the regulatory maze in order to establish an incorporated legal

The differing roles of national and international organisations are contrasted to illustrate the constructive tension that has impacted on both organisations over the past five years. The IPCRG has built on the foundations of national organisations, particularly the GPIAG, but is charting the way internationally to support the delivery of better health outcomes for people with respiratory disease.

Keywords GPIAG, IPCRG, primary care, respiratory disease, organisations, national, international, networks

\section{Contents}

Introduction

Formation of the IPCRG

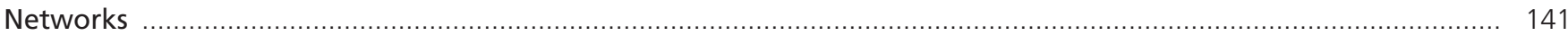

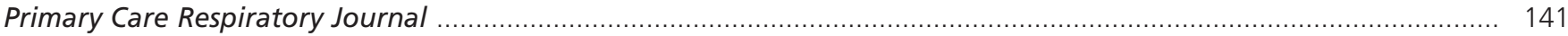

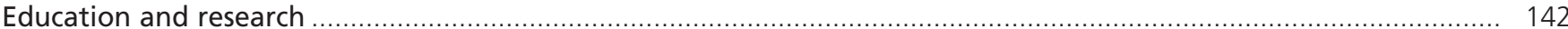

Guidelines development

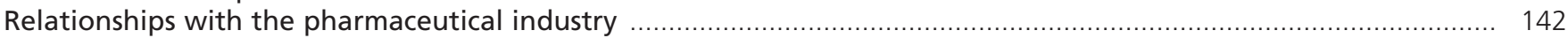

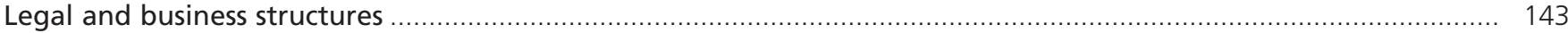

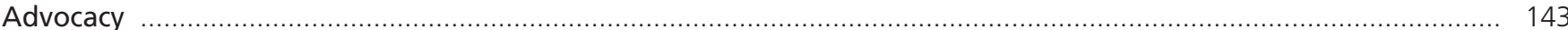

In closing ... …

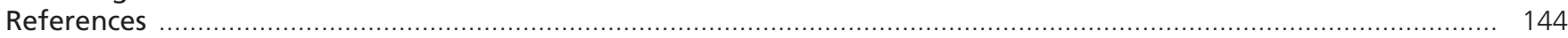

\section{Introduction}

Pigmaei gigantum humeris impositi plusquam ipsi gigantes vident." "A dwarf standing on the shoulders of a giant may see farther than a giant himself."

When the editor suggested a review of "the influence of the
UK General Practice Airways Group (GPIAG) from an international perspective" ${ }^{2}$ the authors opined that it might be a short article! However, on reflection, and after discussion with some key international informants, we recognise the seminal role of the GPIAG in the development of the International Primary Care

* Corresponding author: PO Box 436, Cherrybrook, NSW 2126, Australia Tel: +61294840050 Fax:+61294840073 Email: rtomlins@ozemail.com.au 
Respiratory Group (IPCRG). ${ }^{3}$ This article describes a number of areas in which the GPIAG has influenced the emergence of primary care respiratory medicine as a strong and focussed discipline internationally. But as one of our informants stated, IPCRG is not "the son of GPIAG". Our task is to acknowledge the contribution which the GPIAG has made to the IPCRG, but also to "demonstrate clear blue water" beyond.

\section{Formation of the IPCRG}

The catalyst for the formation of the International Primary Care Respiratory Group (IPCRG) was the GPIAG annual conference held at Robinson College, Cambridge in 2000. At that conference, there were strong themes around common approaches to the delivery of care in 'community' respiratory diseases (asthma, COPD, allergic rhinitis and community acquired pneumonia) and about the differences in the context of healthcare delivery in different countries. For many of us 'from abroad', that conference was the first opportunity to see the potential broader scope for primary care respiratory medicine, to meet others with common aspirations, ${ }^{4-6}$ and to discuss issues about care delivery that were relevant to primary care. The initial suggestion to leverage the enthusiasm and energy of the Cambridge conference to establish an international organisation was adopted with alacrity. It was agreed that the focus should include a biennial conference, research, education and the sharing of resources. However, the challenge that lay before the fledgling society was apparent to only a few. David Price, Thys van der Molen and Mark Levy were trail blazers, showing the way in research, securing of funding and publishing. The willingness of these and others to commit to delivering the vision of the IPCRG resulted in the COPD workshop in Aberdeen in 2001 and the first IPCRG conference in Amsterdam in 2002. In both these endeavours, many of the key figures were also influential members of the GPIAG.

The foundations for the formation of the IPCRG in June 2000 had been laid over previous years. In Australia, for instance, a General Practitioners Asthma Group (GPAG) was established in the early 1990s as part of the National Asthma Campaign - now National Asthma Council Australia (NACA) ${ }^{7}$ - in large part because of lan Charlton's experience as a member of the GPIAG while he was working in the UK. ${ }^{6}$ The NACA had been established in 1989 as a collaboration between organisations of respiratory specialists (and more recently allergists), general practitioners (GPs), community pharmacists and asthma patient support agencies. The GPAG was established as a group within the NACA, not as an independent organisation like the UK GPIAG. The early directions of the NACA were shaped by a National Committee with contributions from all these groups. The GPAG was crucial in developing asthma management guidelines designed for (and accepted by) GPs, and in recognising that implementation of guidelines required attention to the context and the way in which care was delivered. This resulted in the 3+ Visit Plan in 1998, adapting best practice asthma management to the Australian General Practice setting. In 2001, this resource was incorporated into the Australian government's Medicare Benefits Schedule for the management of people with moderate or severe asthma. The contribution of GPs to the work of the NACA has increased as recognition has grown that the majority of asthma care is delivered in the community setting (now 94\% in Australia ${ }^{8}$ ).

The GPIAG also influenced other GP organisations' perception of the scope of primary care respiratory interest. The Cambridge conference clearly highlighted the contribution of primary care physicians to the care of people with respiratory conditions other than asthma. This certainly sparked a broader interest in all airways disorders in Australia and in Canada, with the Family Physician Asthma Group of Canada changing its name to the Family Physician Airways Group of Canada. ${ }^{4}$

\section{Networks}

Networks and communities of practice are the vehicle by which ideas are generated, tested and disseminated, collaborations are established and maintained, and performance can be measured. An international network has an added benefit; that shared sensemaking creates a deeper understanding of what is important and possible, as more and different perspectives are included. So, the IPCRG has had to think harder about issues of incentives, resource availability and what is normal, viewed through a number of lenses. Equally, the IPCRG can be challenged by the successes of its member bodies - including the GPIAG. For instance, the role of primary care respiratory nurses is well developed in the UK, and the IPCRG is therefore wrestling with ideas as to how best to include nursing organisations when primary care nurses are not a universal respiratory resource.

The GPIAG and other national organisations have promoted collaboration in research, education and team-based care delivery. These principles are central to the IPCRG's perception of its role in supporting peers collaborating in a national organisation that works in their context - but a top down approach is not always effective. Successful networks are organic, fluid and bottom-up. National organisational models may not readily translate to other countries.

\section{Primary Care Respiratory Journal}

The Primary Care Respiratory Journal (PCRJ) has been one of the most outward and visible signs of the active partnership between the GPIAG, the IPCRG, and other national primary care respiratory groups. Even before the Cambridge conference, the $P C R J$ International Editorial Advisory Board had engaged a number of primary care experts from other countries and has continued to draw on international expertise ever since. From its inception, the IPCRG recognised the need for, and the value of, a high quality journal devoted to the publication of primary care respiratory research, and therefore gave its active support to the $P C R J$. The 
Journal's willingness to publish quality research carried out in countries outside the UK was also supported by the IPCRG's mentoring program for researchers for whom English is not their first language.

In 2002, the IPCRG entered into an agreement to purchase a number of copies of the $P C R J$ for distribution to members outside the UK. In addition, some IPCRG member countries explored the feasibility of local language supplements. This financial arrangement continued until 2005 when the IPCRG decided after much anguish that it could no longer afford to purchase the Journal. Not surprisingly, this decision was received with dismay by the GPIAG, but both organisations continued to work towards a satisfactory outcome. Following a committee of inquiry, the IPCRG publicised the attributes that it believed were desirable in a peerreviewed journal - in particular, international appeal and wide accessibility rather than just a subscription-based print publication. Those attributes largely describe the current mode of delivery of the $P C R J$ which is Medline-listed and now provides free worldwide internet access to all past and present papers as well as a print publication.

\section{Education and research}

Prior to 2000, the GPIAG had made a unique contribution to the primary care discipline by establishing the GPIAG Chair in Primary Care Respiratory Medicine at Aberdeen.9,10 The consequences of this action have extended well beyond the UK. Professor David Price has contributed both his research skills and the university's organisation, thereby stimulating international studies that have added to the corpus of knowledge and assisted in the training of many researchers outside the UK. The appointment was shared with Professor Thys van der Molen until 2005, when Thys was appointed to a chair in primary care respiratory medicine in Groningen. As the IPCRG's first president, Thys' appointment in Aberdeen was crucial in the formative years of the IPCRG.

The role of the GPIAG research unit at Aberdeen is described elsewhere in this issue of the $P C R J$. One of the benefits for the IPCRG has been the development of an international research network which includes the universities of Groningen and Adelaide, as well as researchers in the USA. The base at Aberdeen has also provided an opportunity for training courses in respiratory medicine to be developed and conducted.

One of the main vehicles for dissemination of information to IPCRG members is the IPCRG website which currently receives over 300 visits per day; visitors can access 380 pages which include guidelines, conference presentations, and resources such as the spirometry opinion sheet. ${ }^{11}$ Website visitors come from Europe (15\%), net addresses (15\%), Australia and Canada (5\%), and commercial interests (34\%), with 30\% unknown. Following the example of the GPIAG and other national respiratory organisations, the IPCRG has produced a number of position statements and information papers on topical issues in the areas of asthma, COPD, infectious disease, rhinitis, health care delivery and diagnostics. These materials are published on the IPCRG website and are available without cost. ${ }^{11}$ IPCRG protects its publications under a Creative Commons Licence.

\section{Guidelines development}

During the last decade, the development of evidence-based guidelines has been a focus for most national respiratory organisations. In addition, GINA, GOLD and ARIA have been active in the publication of international guidelines. GPIAG members have been key contributors to the development of UK respiratory guidelines such as the BTS/SIGN Guidelines for asthma and the NICE Guideline on chronic obstructive pulmonary disease. On its inception, IPCRG shared the same focus on guidelines.

A recurring theme at IPCRG meetings has been the urgent need to develop evidence-based guidelines that take account of the context of delivery of care in different national primary care settings and the unavailability of some diagnostic or treatment services or affordable medicines in many countries.

In 2001, the IPCRG organised a meeting in Berlin of the International Primary Care Airways Group (IPAG), under the joint chairmanship of Professors Martyn Partridge and Onno van Schayck, to develop materials "by and for family doctors that would be appropriate to primary care diagnosis and treatment of chronic respiratory diseases". ${ }^{12}$ Many of the 60 experts contributing to this work were members of the IPCRG and/or the GPIAG. IPAG was supported by GOLD, GINA, ARIA and WHO, and the handbook is endorsed by the IPCRG and the World Organisation of Family Doctors (Wonca). The IPCRG Guidelines and details of the development and validation of a diagnostic tool were published in the Primary Care Respiratory Journal in February $2006 .^{13}$

A parallel initiative in 2001 was the formation of the GINA Dissemination Committee under the chairmanship of Professor Martyn Partridge, with a general practice perspective being provided by Professor Onno van Schayck, Ron Neville and Associate Professor Ron Tomlins. The report of that group on dissemination and implementation of asthma guidelines ${ }^{14}$ is a useful summary of the literature.

Currently, the IPCRG is working on primary care smoking cessation guidelines with primary care experts from nine countries. ${ }^{15}$

\section{Relationships with the pharmaceutical industry}

There are some areas in which the IPCRG, mindful of the experiences of the GPIAG and other national organisations, has been able to pursue a different path.

Over the last 20 years, there has been a growing awareness within the medical profession of the need for greater 
accountability and transparency in accepting sponsorship funding and in joining in collaborative activities with commercial or government agencies. ${ }^{16-18}$ While in its early days the GPIAG established a close relationship with one pharmaceutical company, the relationship of the GPIAG with the pharmaceutical industry has now matured to include a number of corporate sponsors with clear policies to define those relationships. ${ }^{19}$ The success of the GPIAG's approach has been its capacity to continue to publish the $P C R J$ and other resources, run annual conferences, and to endow the GPIAG chair at Aberdeen.

On its inception, the IPCRG determined to maintain an open and equal relationship with pharmaceutical companies through corporate associate membership. A pharmaceutical company can elect to join the IPCRG for a set fee, with entitlements in common with other associate members but no capacity to join the governing committees of the organisation. In addition, companies can elect to fund other research and education activities, with safeguards around editorial independence and right to publish. In addition, pharmaceutical companies can take out commercial sponsorships for the biennial IPCRG conference in accordance with accepted practice. The relationship of national organisations with local pharmaceutical companies can be enhanced by the association of the parent company with the IPCRG. ${ }^{4}$

\section{Legal and business structures}

The business structure of the IPCRG was also influenced in part by the GPIAG experience in registering as an incorporated charity. Following the Annual General Meeting of the IPCRG in Amsterdam in 2002, it was agreed by the IPCRG Executive that the organisation should also seek to incorporate to provide the flexibility needed for an international organisation and to limit the liability of office bearers. The IPCRG was able to build on the GPIAG experience to short-circuit the regulatory maze. At the same time, the IPCRG recognised that it required a different business model, with a virtual organisation and infrastructure, to ensure that the funds at our disposal were utilised for our primary purposes. As an 'organisation of organisations,' with an international executive committee and language barriers, trading across national boundaries, and with different approaches to regulation and taxation, the IPCRG has had to address issues that are not germane to a national organisation.

In large part, the operations of the IPCRG are the responsibility of our staff with regular teleconferences to manage policy issues. The IPCRG seeks to define its relationships with its partners through contracts or agreements that specify mutual expectations and responsibilities. These contracts are scrutinised by a governance committee including experts in accountancy and managing risk (and only one doctor...). One issue on which all the informants for this article agreed $d^{4-6,9,10,20}$ was the contribution of our Executive Officer (Sian Williams) and Business Manager (Sam
Louw) to the development of the IPCRG. Both staff had previously worked with the GPIAG and understand both the challenges of working with doctors in the respiratory field and the opportunities for enhancing the care of people with respiratory illnesses.

The partnership model that has supported the PCRJ over the past few years has also benefitted our colleagues in Asia. The National Asthma Council Australia has been funded by a pharmaceutical company to work with respiratory organisations in a number of Asian Pacific countries to guide the development of asthma councils or lung foundations as appropriate to that country. In some countries, the relationship between primary and secondary care is different to the European experience, and the IPCRG has been asked by NACA to bring an international perspective to promote high quality primary care. The Speakers Bureau established by the IPCRG facilities this process by providing a source of funding for international primary care experts to participate.

\section{Advocacy}

One of the areas in which the GPIAG has been particularly strong in recent years is in advocating greater resources for primary care and improving the care of people with respiratory illness in the UK. Other national organisations have taken a similar role. The GPIAG has promoted the extension of evidence-based performance indicators for respiratory conditions in the Quality Outcomes Framework (QOF) of the GP General Medical Services Contract and has also taken the lead in the development of GPs with a Special Interest (GPwSIs). This model has been adopted in Canada. ${ }^{4}$

The IPCRG has moved slowly into the area of advocacy, but is now developing a useful presence within Europe. It works closely with the European Federation of Allergy and Airways Diseases Patients Associations (EFA) and has lobbied successfully for changes to the European Medicines Agency (EMEA) guideline on pharmacovigilance for children. In addition, the IPCRG successfully lobbied for the inclusion of respiratory illness and allergy in the Seventh Framework Programme for Research, FP7, with funding of 6 billion euros over 7 years. It is building relationships with GA²LEN, a European-Commission funded respiratory and allergy research network across 25 academic institutions. Through its membership of the Global Alliance for Respiratory Disease (GARD) and its association with the World Organisation of Family Doctors (Wonca), it is well placed to contribute a primary care perspective and to advocate for more appropriate allocation of resources to improve health.

\section{In closing ...}

We stand on the shoulders of others, and the impact of the UK GPIAG has been significant well beyond the British Isles. Increasingly, information and communication technologies will 
facilitate international links with national organisations, groups and individuals leading to collaboration in ways that have yet to be devised. One thing will be crucial - developing objective ways to assess the outcomes of care delivery in normal clinical practice. In this way, we will be better placed to test the relevance of 'traditional RCT-based' guidelines in the primary care setting, and to determine how effectively clinical practice changes in response to new knowledge. The last 20 years have bridged the transition from empiricism to 'evidence-informed' practice, but the outcomes of care in many countries today remain poor. There is a huge and largely untapped potential for reciprocal learning through population-based approaches and working with patients in different health care systems. A network of national organisations sharing their expertise with others is an achievable goal, facilitated by international 'organisations of organisations' like the IPCRG, which acknowledges that the UK GPIAG has been a seminal influence on its development.

\section{Conflict of interest declaration}

There were no conflicts of interest for the authors in the preparation of this article..

\section{References}

1. "A dwarf standing on the shoulders of a giant may see farther than a giant himself", attributed to Bernard of Chatres in the 10th century. This saying is inscribed on the side of the standard design of UK 2 pound coins.

2. Mark Levy Personal communication dated 10 March 2007.

3. See www.theipcrg.org

4. Alan Kaplan Personal communication dated 11 April 2007

5. Jim Reid Personal communication dated 11 April 2007.

6. H John Fardy Personal communication dated 10 April 2007.

7. For further information, see www.nationalasthma.org.au

8. See http://www.asthmamonitoring.org/index.htm for further information about the Australian Centre for Asthma Monitoring (ACAM).

9. David Price Personal communication dated 11 April 2007.

10. Thys van der Molen Personal communication dated 10 April 2007.

11. For further information, see www.theipcrg.org/resources/index.php

12. See www.theipcrg.org/guidelines/ipag_backgrounder.php

13. Accessed at www.thepcrj.org/journ/guidelines.php on 25 April 2007.

14. Accessed at www.ginasthma.com/Reportltem.asp? $|1=2 \&| 2=2 \&$ intld=96 on 25 April 2007.

15. Onno van Schayck Personal communication dated 21 April 2007.

16. Bero LA. Accepting commercial sponsorship. BMJ 1999;319;653-4.

17. Lexchin J, Bero LA, Djulbegovic B, Clark O. Pharmaceutical industry sponsorship and research outcome and quality: systematic review. BMJ 2001;322:569-70.

18. Evans S, Pocock S. Societal responsibilities of clinical trial sponsors. Lack of commercial pay off is not a legitimate reason for stopping a trial. BMJ 2001;322;569-70.

19. Accessed at www.gpiag.org/legal/october_2006/Endorsement_partnership\% 20_policy_Oct\%2006.pdf on 26 April 2007.

20. John Haughney Personal communication dated 10 April 2007.

\section{Available online at http://www.thepcrj.org}

